\title{
O ENSINO DE LITERATURA: RELATO DE UMA PRÁTICA
}

\author{
Aline Cassol Daga ${ }^{1}$ \\ Amanda Machado Chraim ${ }^{2}$
}

Resumo: Este texto surge como um relato da experiência obtida no estágio docente em Língua Portuguesa realizado com uma turma do Ensino Médio numa escola de Florianópolis, durante o qual procuramos desenvolver um trabalho em sala de aula com a leitura de textos literários, proporcionando aos alunos um primeiro contato o mais prazeroso possível com a literatura. Esse trabalho revelou-nos que a literatura pode e deve ser trabalhada de forma livre e espontânea, fazendo com que os alunos interajam com ela, sem as formas prontas encontradas em muitos livros didáticos.

Palavras-chave:Literatura. Ensino. Prazer. 
Não entender, do modo como falo, é um dom. Não entender, mas não como um simples de espírito. O bom é ser inteligente e não entender. É uma benção estranha, como ter loucura sem ser doida. É um desinteresse manso, é uma doçura de burrice. Só que de vez em quando vem a inquietação: quero entender um pouco. Não demais: mas pelo menos entender que não entendo.

Clarice Lispector

\section{Introdução}

$\mathrm{Na}$ vida escolar, como parte do processo de aprendizagem no Ensino Médio, mais especificamente nas aulas de literatura/português, realiza-se a leitura de diversos textos escolhidos pelo professor ou presentes nos livros didáticos bem como, leitura de obras de diversos autores, em sua maioria cobradas pelo vestibular. Nessas leituras, o aluno se depara com autores consagrados, como Machado de Assis, Manuel Bandeira, Carlos Drummond de Andrade. Ao estudá-los, primeiramente conhecem suas trajetórias de vida e depois suas obras.

O que os livros didáticos costumam apresentar por meio de fragmentos textuais é uma história da literatura. Cada uma das unidades dos livros didáticos, na sua maioria, condiz com uma escola literária. Dentro dessas unidades percebe-se a seguinte estrutura: primeiramente faz-se uma breve explanação do momento histórico vigente da época da corrente literária, logo depois se apresentam os autores mais representativos, os traços biográficos desses. Em seguida, são mostrados alguns trechos das obras do autor estudado. Tudo isso, além de não possibilitar o contato do aluno com o texto, já que apresenta pequenos fragmentos, acaba por enfatizar apenas a designação e delimitação de períodos literários, minimizando a literatura. $\mathrm{O}$ gosto que poderia ser despertado nos alunos não aflora, pois o contato com o objeto da literatura, ou seja, com o texto, não acontece como deveria.

Diante disso, procuramos desenvolver um projeto de estágio que valorizasse e priorizasse o contato dos alunos com os textos, sem preocupações com definições de escolas literárias. Por se tratar de uma turma de primeiro ano do ensino médio, cujo contato com a literatura seria 
teoricamente o primeiro, optamos por textos literários de Clarice Lispector e Luiz Fernando Veríssimo, por exemplo, na tentativa de provocar nos alunos um amor pela literatura, o qual, já imaginávamos, não seria à primeira vista, mas por que não à segunda?

A solicitação da professora da turma foi para que os conteúdos trabalhados fossem sobre o Trovadorismo e o Humanismo, períodos literários inclusos na cronologia da literatura portuguesa. Segundo ela, a opção por destinar o que é considerado como ensino de literatura às estagiárias partiu de um gosto que ela, particularmente, não tem pelo assunto, isto é, por não gostar de "ensinar" literatura, preferindo o "ensino" da "gramática", destinou esse conteúdo às estagiárias. A docente revelou ainda que considera o ensino de literatura chato, pois esse exige muitos conhecimentos de História, por exemplo. Dessa forma, percebemos que a docente se pauta no ensino tradicional de literatura, feito com ênfase no comentário das características de cada movimento literário e no estabelecimento de panoramas históricos, desenrolando a exposição em ordem cronológica em vez de exame direto das obras no próprio texto. Um estudo mais detalhado da obra em paralelo com textos da atualidade, certamente levariam o aluno a questionar e interagir com os dois contextos.

\section{O ensino de literatura: algumas constatações}

O ensino de língua portuguesa no Ensino Médio tomava (ainda toma?) como base dois eixos: classificação e memorização de nomenclatura gramatical e sistematização da história da literatura. O texto, por inúmeras vezes, era considerado um "respiro", uma pausa "lúdica" no "conteúdo" que deveria ser passado para os alunos.

Sem dúvida, a literatura, em alguns planejamentos escolares do Ensino Médio, ainda é estudada como uma disciplina à parte, como se tivesse pouca ou nenhuma relação com a Língua Portuguesa. Em muitos casos, o que se propõem é uma lista de informações sobre a literatura: nomes de autores, obras e cronologias de movimentos literários; resumos de romances e estudos estruturais de poemas. A leitura, a fruição, a experiência efetiva com o texto literário fica relegada a um segundo plano.

Leite (2007) aponta que tradicionalmente a escola utiliza uma noção de literatura que conjuga três papéis distintos: a literatura como instituição 
nacional; a literatura como disciplina escolar que se confunde com a história literária; a literatura como cada texto consagrado pela crítica como sendo literário. Entretanto, sugere que a literatura deve ser tomada como "[...] qualquer texto, mesmo não consagrado, com intenção literária, visível num trabalho da linguagem e da imaginação, ou simplesmente esse trabalho enquanto tal" (LEITE, 2007, p.21). Essa concepção mais ampla de literatura fundamenta-se primordialmente no trabalho com a linguagem.

Para Lajolo (1994), a decisão do que fazer com o texto literário em sala de aula parece, em muitos casos, ainda não ser competência do professor, mas das editoras. O que os livros didáticos costumam apresentar por meio de fragmentos textuais é uma história da literatura. Cada uma das unidades dos livros didáticos, na sua maioria, condiz com uma escola literária. Dentro dessas unidades percebe-se a seguinte estrutura: primeiramente contextualiza-se o aluno no período histórico da corrente literária a ser estudada, ou seja, faz-se uma breve explanação do momento histórico vigente da época da corrente literária, logo depois se apresentam os autores mais representativos, os traços biográficos desses, assim como do contexto em que o autor viveu. Em seguida, são mostrados alguns trechos das obras do autor estudado. Em algumas unidades são citados também outros autores (aqueles que não são consagrados, porém da mesma época, da mesma escola literária do autor em destaque) e há apenas um breve resumo de suas vidas. Na sequência, são indicados exercícios a serem feitos sobre as obras e trechos das obras dos autores anteriormente apresentados. Tudo isso, além de não possibilitar o contato do aluno com o texto, já que apresenta pequenos fragmentos, a ênfase em designação e delimitação de períodos literários acaba por diluir aquilo que deveria ser o ensino de literatura. O gosto que poderia ser despertado nos alunos não aflora, pois o contato com o objeto da literatura, ou seja, com o texto, não acontece como deveria.

Segundo Lajolo \& Zilberman (1996, p.120),

O livro didático é o primo-pobre da literatura, texto para ler e botar fora, descartável porque anacrônico: ou ele fica superado dados os progressos da ciência a que se refere ou o estudante o abandona, por avançar em sua educação. 
Não se trata de desprezar o estudo da literatura como sistema de obras e autores para o qual se fazem necessárias informações históricas, mas segundo Chiappini (2007, p. 22), é importante, “ [...] sobretudo nos primeiros anos de contato com os textos, exercitar a leitura e a escrita, para que a reflexão histórica e teórica sobre eles se dê a partir de uma vivência e do processo que os gera: o trabalho criativo com a linguagem, a prática da expressão livre".

Deve-se permitir um contato mais sensível com a obra literária, de tal modo que a análise de um texto torne possível alguma reflexão sobre o modo de encarar o mundo e a realidade. Isso não significa que se deva deixar de considerar a importância da contextualização da obra. Uma síntese dos movimentos literários é relevante desde que tenha a finalidade de apresentar um referencial teórico de consulta para o aluno sobre a história da literatura. Assim, o aluno tem a chance de observar e compreender uma das mais tradicionais classificações literárias e, além disso, refletir sobre o papel e os objetivos dessas categorizações.

O texto literário deve ser discutido e analisado por professores e alunos, numa relação de diálogo, trocas e respeito à fala e à voz do aluno, bem como às suas leituras anteriores. No entanto, alguns professores ao utilizarem fragmentos de textos literários para as análises gramaticais, acabam por deixar de lado o ensino de literatura. Por outro lado, os que ainda ensinam a Literatura como disciplina optam por serem guiados pelos livros didáticos, poucos são os profissionais que recorrem a outros meios. A preocupação com o ensino de literatura no ensino médio está voltada à preparação de alunos para processos de seleção como o vestibular, formando assim, alunos que apenas decoram o que está ali copilado, incapazes de procurarem além livro didático, módulo ou apostila.

Com base na definição dada por Afrânio Coutinho (apud NICOLA, 2005, p. 258) de que "a literatura é uma arte, a arte da palavra, isto é, um produto da imaginação criadora, cujo meio específico é a palavra, e cuja finalidade é despertar no leitor ou ouvinte o prazer estético", acreditamos que o principal objetivo deva ser o contato do aluno com o texto, mesmo que esse contato provoque um estranhamento, uma espécie de "choque" num primeiro momento. Não entendemos o ensino de literatura como o ensino de escolas literárias, por isso, procuramos propiciar aos alunos um maior número de leituras, ainda que a interlocução feita por eles hoje não seja a esperada pelos docentes. 


\section{A literatura como impulso para a imaginação}

Parece-nos plausível começarmos com a seguinte indagação: afinal, para que serve a literatura?

A resposta para essa pergunta varia com o tempo e com as pessoas. Evidentemente, a função de uma obra literária depende dos objetivos e das intenções do autor, mas os leitores também têm maneiras diferentes de ler e são levados a abrir um livro por motivos diferentes. Alguns buscam na literatura apenas um divertimento sem grandes consequências para a vida; outros, um instrumento de transformação e de aperfeiçoamento. Uns consideram a obra literária apenas um artefato estético, criado para a contemplação da beleza; já outros esperam que seja um veículo de análise e de crítica em relação à sociedade e à vida.

Parafraseando Nietzsche, diria que a literatura serve para tudo e para nada. Hoje, para um mundo que parece tomar conta de todos os nossos sentidos e prazeres, talvez para nada. Vejo a literatura mais como uma instância cultural que facilita a configuração, por parte do usuário, de variados tipos de reação, desde a alienação escandalosa ao engajamento radical, do refinamento intelectual ao dogmatismo paralisante das catequeses políticas - em síntese: o mergulho na loucura ou ao repouso na sabedoria. (GONÇALVES FILHO, 2000, p. 34).

Como arte, a literatura é o ponto de partida privilegiado para a formação de leitores. Suas potencialidades provocadoras do pensamento são inesgotáveis. Por meio dela, a ficção se integra com a realidade, pois sua matéria-prima é a experiência, a observação, a reflexão e o sonho. Ao unir realidade e fantasia, o livro de literatura abarca todos os temas da vida, mobilizando o interesse de qualquer pessoa, em qualquer idade. Não há instrumento mais completo para levar à reflexão, à crítica e à criação do que a literatura.

Ao alimentar o imaginário, um bom livro leva a criança, o jovem e o professor a perguntar e a procurar respostas, desenvolvendo, como nenhum outro instrumento, as capacidades de observar, analisar, refletir, criticar e criar, com senso de humor e liberdade. 
A leitura de qualquer texto, assim como a de textos poéticos deve ser algo prazeroso, que dê oportunidades de viajar pelo tempo e construir conhecimentos e possibilidades de discernir e compreender melhor o mundo, os tempos passado, presente e futuro. Para Barthes (2002), a leitura é uma forma de felicidade e de gozo, assim como a escrita é o seu próprio desejo; quando o autor escreve um texto ele o faz em comunhão com o prazer, e aquele, automaticamente, deseja o leitor. O que impulsiona o leitor para um texto é o prazer. Se o leitor não sentir prazer em ler, não conseguirá percorrer o texto, o máximo que ele fará será uma leitura superficial.

No entanto, o texto literário exige um contato solitário e profundo, e os alunos precisam conscientizar-se disso, acostumando-se a conviver com a solidão de uma boa leitura, a qual propicia uma experiência única com o texto literário. O que acaba ocorrendo é que muitos professores, na ânsia de despertar o gosto nos alunos pela literatura, preocupam-se em armar um "espetáculo" com leituras jogralizadas, resumos comentados ou encenações de obras literárias, estrelando muitas vezes para uma platéia desatenta e desinteressada.

A Literatura, como expressão humana, conduz ao autoconhecimento e por sua natureza ficcional, à imaginação. Num mundo tão conturbado como o nosso, a literatura é o espaço da criação, da liberdade de pensar, retirando a criatura da escravidão de pensamentos, da passividade própria de uma sociedade dominadora. Ela desenvolve a criatividade humana, leva a refletir sobre o indivíduo e a sociedade.

Por isso, a despeito de todo desprezo que possa sofrer nas mãos de determinadas políticas educacionais, a Literatura deve ser trabalhada de forma livre e criativa, aproveitando seu permanente diálogo com outras artes como a música e o teatro, para favorecer uma crescente aproximação do texto literário com o aluno. A Literatura precisa ser encarada como fenômeno artístico, considerada em sua natureza educativa por excelência, porque traz valores, crenças, ideias, pontos de vista de seus autores, que podem enriquecer a vida daqueles que a leem. Não deve estar presa a modismos pedagógicos e sim ser considerada como uma atividade prazerosa de conhecimento do ser humano e das diversas funções 
da linguagem, entre elas a função poética, pois retrata e recria as questões humanas universais, numa linguagem esteticamente trabalhada, transgressora da rotina cotidiana.

\section{Notas}

${ }^{1}$ Aline Cassol Daga (Mestranda no programa de Pós-Graduação em Linguística da Universidade Federal de Santa Catarina e pesquisadora do NELA - Núcleo de Estudos em Linguística Aplicada)

${ }^{2}$ Amanda Machado Chraim (Mestranda no programa de Pós-Graduação em Linguística da Universidade Federal de Santa Catarina e pesquisadora do NELA - Núcleo de Estudos em Linguística Aplicada)

\section{Referências}

BARTHES, Roland. O prazer do texto. Tradução de J. Guinsburg. 3. ed. São Paulo: Perspectiva, 2002.

GONÇALVES FILHO, Antenor Antônio. Educação e literatura. Rio de Janeiro: DP\&A, 2000.

LAJOLO, Marisa. O que é literatura. Ed. Brasiliense, 1984.

. A leitura literária na escola. In: Do mundo da leitura para a leitura do mundo. 2 ed. São Paulo: Ática, 1994, p. 11-16.

LAJOLO, Marisa, ZILBERMAN Regina. Livro didático, matéria da literatura. In: A formação da leitura no Brasil. São Paulo: Ática, 1996.

LEITE, Lígia Chiappini de Moraes. Gramática e literatura: desencontros e esperanças. In: GERALDI, J. W. (org.). O texto na sala de aula. 4 ed. São Paulo: Ática, 2007, p. 17-25.

NICOLA, José de. Português: ensino médio. São Paulo: Scipione, 2005.

ZILBERMAN, Regina. A leitura na escola. In: Leitura em crise na escola: as alternativas do professor. 10 ed. Porto Alegre: Mercado Aberto, 1991. 


\begin{abstract}
:
The Teaching of Literature: report of a practice

This is a report of the experience obtained on the teaching internship in Portuguese Language studies of a secondary education school in Florianópolis, where we presented the students with literature reading material, aiming to present them a pleasant and enjoyable first contact with the subject. This project revealed that literature can and must be presented as free and sponteneous as possible, allowing the students to interact with it, moving away from the pre-conceived formulas suggested in some handbooks.
\end{abstract}

Keywords: Literature. Teaching. Pleasure.

Recebido em junho de 2009

Aceito em novembro de 2009 